\title{
Spatial and decadal variations in satellite-based terrestrial evapotranspiration and drought over Inner Mongolia Autonomous Region of China during 1982-2009
}

\author{
Zhaolu Zhang ${ }^{1}$, Hui $\mathrm{Kang}^{2}$, Yunjun $\mathrm{YaO}^{3, *}$, Ayad M Fadhil ${ }^{4}$, \\ YUHU ZHANG ${ }^{5}$ and KUN JiA ${ }^{3}$ \\ ${ }^{1}$ School of Resources and Environmental Engineering, Shandong University of Technology, \\ Zibo 255000, Shandong, China. \\ ${ }^{2}$ China Mobile Group Beijing Co., Ltd., Beijing 100027, China. \\ ${ }^{3}$ State Key Laboratory of Remote Sensing Science, Faculty of Geographical Science, Beijing Normal University, \\ Beijing 100875, China. \\ ${ }^{4}$ Earth Sciences Department, Faculty of Science, University of Kufa, Najaf 34003, Iraq. \\ ${ }^{5}$ College of Resource Environment and Tourism, Capital Normal University, \\ Beijing 100048, China. \\ *Corresponding author. e-mail: boyyunjun@163.com
}

MS received 14 September 2016; revised 29 April 2017; accepted 9 May 2017; published online 2 December 2017

Evapotranspiration $(E T)$ plays an important role in exchange of water budget and carbon cycles over the Inner Mongolia autonomous region of China (IMARC). However, the spatial and decadal variations in terrestrial $E T$ and drought over the IMARC in the past was calculated by only using sparse meteorological point-based data which remain quite uncertain. In this study, by combining satellite and meteorology datasets, a satellite-based semi-empirical Penman ET (SEMI-PM) algorithm is used to estimate regional ET and evaporative wet index (EWI) calculated by the ratio of $E T$ and potential $E T(P E T)$ over the IMARC. Validation result shows that the square of the correlation coefficients $\left(R^{2}\right)$ for the four sites varies from 0.45 to 0.84 and the root-mean-square error (RMSE) is $<0.78 \mathrm{~mm}$. We found that the ET has decreased on an average of $4.8 \mathrm{~mm}$ per decade $(p=0.10)$ over the entire IMARC during 1982-2009 and the EWI has decreased on an average of $1.1 \%$ per decade $(p=0.08)$ during the study period. Importantly, the patterns of monthly EWI anomalies have a good spatial and temporal correlation with the Palmer Drought Severity Index (PDSI) anomalies from 1982 to 2009, indicating EWI can be used to monitor regional surface drought with high spatial resolution. In high-latitude ecosystems of northeast region of the IMARC, both air temperature $\left(T_{a}\right)$ and incident solar radiation $\left(R_{s}\right)$ are the most important parameters in determining ET. However, in semiarid and arid areas of the central and southwest regions of the IMARC, both relative humidity $(\mathrm{RH})$ and normalized difference vegetation index (NDVI) are the most important factors controlling annual variation of $E T$.

Keywords. Terrestrial evapotranspiration; evaporative wet index; inner Mongolia autonomous region; surface drought. 


\section{Introduction}

Evapotranspiration $(E T)$ is an important process in an ecosystem water budget, energy balance, and carbon cycles, and strongly affects global or regional surface dry conditions and climate change (Priestley and Taylor 1972; Wang and Dickinson 2012; Yao et al. 2014, 2016; Zhang et al. 2016). Over the last three decades, substantial changes in $E T$ associated with precipitation $(P)$, river discharge $(Q)$ and soil moisture (SM), occurred in the Inner Mongolia autonomous region of China (IMARC) (Shi et al. 2007; Yang and Zhou 2011; Xia et al. 2014; Cao et al. 2015). Numerous evidences reveal that the variations in water budget are influencing ecosystem processes and surface drought in the IMARC (Xiao et al. 2009; Xia et al. 2014). However, there are still large errors to estimate $E T$ for detection of the variations in water budget and surface drought in the IMARC. Therefore, it is crucial to improve ET estimation to understand the long-term variations in water budget and drought as well as their dominant climate factors.

Remote sensing has provided many land surface biophysical parameters, such as leaf area index (LAI), normalized difference vegetation index (NDVI), albedo and land surface temperature (LST), which characterize terrestrial ET and drought in the IMARC. Previous numerous studies showed satellite-based ET algorithms improved ET estimation and drought monitoring in the IMARC since 1980's (Yang and Zhou 2011; Yao et al. 2013; Li et al. 2014; Xia et al. 2014). For example, Xia et al. (2014) used the regression tree method and satellite-derived NDVI data to estimate regional $E T$ in the grassland ecosystems of dryland East Asia, and found that the algorithm explained $76 \%$ of the variations of ET observations to characterize a decreasing trend over $61 \%$ of the dryland East Asia region. However, the data-based ET algorithms require a lot of ground-observations data to train the model and there are limited training data available (Yang et al. 2006; Jung et al. 2010, 2011). In contrast, the process-based ET algorithms require fewer training data but they have low performance in the grassland ecosystems in this region due to their complex parameterization schemes (Yao et al. 2013, 2015a; Ershadi et al. 2014).

Several satellite-based hybrid ET algorithms by combining empirical and physical algorithms (e.g., semi-empirical Penman algorithm, hybrid
Priestley-Taylor algorithm, semi-empirical exponential algorithm) have been widely used to estimate regional and global ET and drought using eddy covariance $(E C)$, meteorological, and satellite observations (Wang et al. 2010; Yao et al. 2015b). Among these hybrid algorithms, semiempirical Penman algorithm proposed by Wang et al. (2010) can detect global and regional ET variations on a scale of several decades because it considers the impact of incident solar radiation $\left(R_{s}\right)$, air temperature $\left(T_{a}\right)$, vapour pressure deficit (VPD), relative humidity (RH), NDVI, and wind speed (WS) (Skidmore et al. 1969; Wang et al. 2010; McVicar et al. 2012). Previous comparison of measured and estimated daily ET at 64 globally distributed flux tower sites indicated that 16 day average daily ET can be reasonably estimated with a squared correlation coefficient $\left(R^{2}\right)$ of 0.88 and average root mean square error (RMSE) of $0.6 \mathrm{~mm}$ (Wang et al. 2010). Currently, selection of this algorithm for the regions covered with mainly grassland, such as IMARC, is still not documented in current contributions. Moreover, the spatiotemporal variations in terrestrial $E T$ and drought over the IMARC in the past were calculated by only using sparse meteorological point-based data that remain quite uncertain (Yang et al. 2012a).

In this study, we used the semi-empirical Penman algorithm driven by long-term satellite and meteorology datasets to estimate ET in the IMARC. We then used an evaporative wet index (EWI) derived from ET and potential ET (PET) to assess the terrestrial drought and the variations in ET and EWI across the IMARC. Our study has three major objectives. First, we evaluate the capacity of the semi-empirical Penman algorithm to estimate ET and EWI at a regional scale. Second, we analyze the spatial and decadal variation in ET, EWI, PET and climate factors during 1982 2009. Finally, we detect the correlations between ET and meteorological variables.

\section{Study area and data}

\subsection{Study area}

The study area is Inner Mongolia autonomous region of China (IMARC), which is located in the north China, containing most of China's border with Mongolia and a small section of the border with Russia situated between $37.40^{\circ}-53.38^{\circ} \mathrm{N}$ and $97.20^{\circ}-126.07^{\circ} \mathrm{E}$ (Guo et al. 2014). The total area 
of the study is approximately 1.18 million $\mathrm{km}^{2}$ (figure 1). Except for the relatively humid Da Hinggan Ling Mountain area, most part of Inner Mongolia is arid, semi-arid or semi-humid from west to east (Liu et al. 2016). The region is dominated by monsoon climate pattern, where high temperatures and variable rainfall occur in the summer and cold northwesterly winds occur in winter (Brogaard et al. 2005; Yang et al. 2012b). There is an increase in precipitation and a decrease in temperature from southwest to northeast of the IMARC. The annual temperature in the IMARC ranges from $-5^{\circ}$ to $10^{\circ} \mathrm{C}$ and the mean annual precipitation rate is $30-500 \mathrm{~mm}$. The cold temperate humid and medium temperate sub-humid region in the northeast is dominated by the forest. The medium temperate semiarid region in the central area is dominated by grass and cropland. The land cover type of the medium temperate arid region in the southwest is a desert (Wu et al. 2003). Figure 1 shows the International Geosphere-Biosphere Programme (IGBP) land cover types from MOD12 product that characterizes the study region.

\subsection{Data}

Here we used the ground-measured daily $R_{s}, T_{a}$, vapour pressure (e), $\mathrm{RH}$ and $P$ during 19822009 from China Administration of Meteorology
(CMA), which includes 51 stations. The MOD16 ET product (2001-2009) (Mu et al. 2011) with temporal resolution of 8 days and spatial resolution of $1 \mathrm{~km}$ was acquired from the University of Montana's Numerical Terradynamic Simulation group to evaluate estimated ET. All meteorological variables and MOD16 ET product were interpolated into 0.1 degree gridded datasets using bilinear interpolation method. Land cover data of 2008 was derived from the MODIS Land Cover product (MOD12Q1) with 0.05 degree. We also used the bimonthly normalized difference vegetation index (NDVI) products derived from the Global Inventory Modelling and Mapping Studies (GIMMS) group (Tucker et al. 2005) with a spatial resolution of $8 \mathrm{~km}$ to estimate actual ET and EWI. To better correspond with the gridded meteorological data, the land cover data and the GIMMS-NDVI data were converted to a resolution of $0.1^{\circ} \times 0.1^{\circ}$ using bilinear interpolation. The daily NDVI values were temporally interpolated from the bimonthly averages using linear interpolation. We also used the monthly Palmer Drought Severity Index (PDSI) product (Dai et al. 2004) derived from the NCAR CGD's Climate Analysis Section dataset with a 2.5 degree spatial resolution, for the period 1982-2009. We also interpolated the PDSI products into 0.1 degree from a 2.5 -degree spatial resolution.

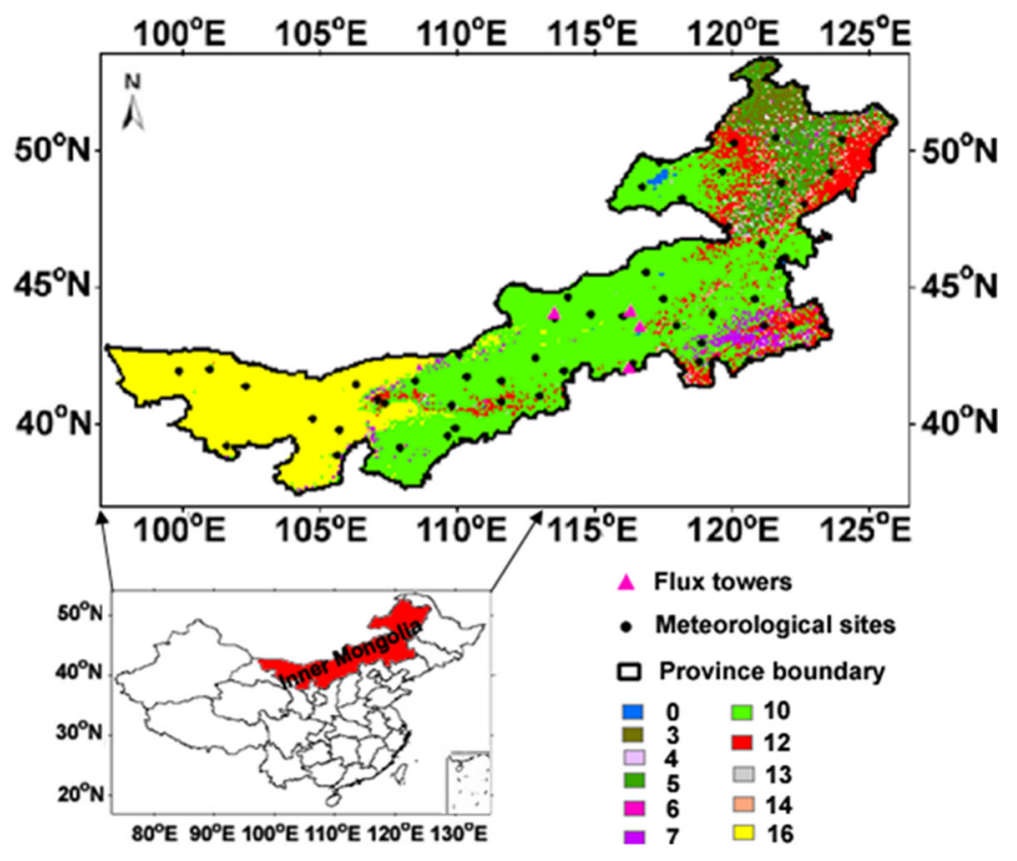

Figure 1. The map of the study area. IGBP land cover types are shown: 0: water body; 1: evergreen needleleaf forest; 2: evergreen broadleaf forest; 3 : deciduous needleleaf forest; 4: deciduous broadleaf forest; 5 : mixed forest; 6: closed shrubland; 7: open shrubland; 8: woody savanna; 9: savanna; 10: grassland; 11: permanent wetland; 12: crop land; 13: urban/build up; 14: crop land/natural vegetation mosaic; 15: snow/ice; and 16: barren lands. 
Table 1. Site name, location, land cover, elevation, time period, network and reference of the EC data used in this study.

\begin{tabular}{|c|c|c|c|c|c|c|}
\hline Site name & Latitude, longitude & Land cover & $\begin{array}{l}\text { Elevation } \\
(\mathrm{m})\end{array}$ & Time period & Network & Reference \\
\hline $\begin{array}{l}\text { Xilinhot Inner Mongolia } \\
\text { fenced typical steppe } \\
\text { site (XFS) }\end{array}$ & $44.13^{\circ} \mathrm{N}, 116.33^{\circ} \mathrm{E}$ & Grassland & 1187 & $2004-2006$ & LathuileFlux & $\begin{array}{l}\text { Wang et al. } \\
\text { (2008) }\end{array}$ \\
\hline $\begin{array}{c}\text { Xilinhot Inner Mongolia } \\
\text { grassland site (XLG) }\end{array}$ & $43.55^{\circ} \mathrm{N}, 116.67^{\circ} \mathrm{E}$ & Grassland & 1250 & $\begin{array}{l}\text { 2006(January-- } \\
\text { December) }\end{array}$ & LathuileFlux & $\begin{array}{l}\text { Chen et al. } \\
\text { (2009) }\end{array}$ \\
\hline $\begin{array}{c}\text { Dongsu Inner Mongolia } \\
\text { grassland site (DSG) }\end{array}$ & $44.09^{\circ} \mathrm{N}, 113.57^{\circ} \mathrm{E}$ & Grassland & 970 & $\begin{array}{l}\text { 2008(January- } \\
\text { December) }\end{array}$ & $C E O P$ & $\begin{array}{l}\text { Zeng et al. } \\
\text { (2011) }\end{array}$ \\
\hline $\begin{array}{c}\text { Duolun Inner Mongolia } \\
\text { grassland site (DLG) }\end{array}$ & $42.05^{\circ} \mathrm{N}, 116.28^{\circ} \mathrm{E}$ & Grassland & 1350 & $\begin{array}{l}\text { 2006(January- } \\
\text { December) }\end{array}$ & LathuileFlux & $\begin{array}{l}\text { Chen et al. } \\
\text { (2009) }\end{array}$ \\
\hline
\end{tabular}

To validate the actual $E T$, we used the groundmeasured $E T$, sensible heat flux $(H)$, ground heat flux $(G), T_{a}, \mathrm{RH}, \mathrm{WS}, e, R_{s}$ and net radiation $\left(R_{n}\right)$ derived from four flux tower sites (table 1 ). The data are provided by LathuileFlux and the Coordinated Enhanced Observation Network of China (CEOP). The data cover 2004-2008 and the land-cover type at four sites is grassland. The turbulent flux data are measured according to the eddy covariance $(E C)$ method. These flux datasets include half-hourly ground-measured data. The site descriptions for all 22 sites including name, location, vegetation type, years of data available, and references are provided in table 1 . Because the $E C$ method suffers from an energy imbalance problem, where the measured available energy $\left(R_{n}-G\right)$ is greater than the sum of the measured ET and $H$ (Jung et al. 2010), the method proposed by Twine et al. (2000) has been chosen to correct the ET values at four sites and the corrected method is as follows:

$$
L E=\frac{\left(R_{n}-G\right)}{\left(L E_{\text {ori }}+H_{\text {ori }}\right)} \times L E_{\text {ori }}
$$

Here $L E$ is the corrected latent heat flux. $H_{\text {ori }}$ and $L E_{\text {ori }}$ are the uncorrected sensible heat flux and latent heat flux, respectively.

\section{Methods}

\subsection{Satellite-based semi-empirical Penman ET algorithm}

Because a semi-empirical Penman ET (SEMI-PM) algorithm proposed by Wang et al. (2010) can be used for monitoring regional ET on decadal scales, we have selected this algorithm to estimate terrestrial $E T$ in the IMARC for analyzing spatiotemporal variation in ET. This algorithm can be expressed as:

$$
\begin{aligned}
E T= & a_{1}\left(E T_{E}+E T_{A}\right)+a_{2}\left(E T_{E}+E T_{A}\right)^{2} \\
E T_{E}= & \frac{\Delta}{\Delta+\gamma} R_{s}\left[a_{3}+a_{4} N D V I\right. \\
& \left.+R H D\left(a_{5}+a_{6} N D V I\right)\right] \\
E T_{A}= & \frac{\gamma}{\Delta+\gamma} W S\left[a_{7}+R H D\left(a_{8}\right.\right. \\
& \left.\left.+a_{9} N D V I\right)\right] V P D
\end{aligned}
$$

where $a_{1}=0.819, a_{2}=0.0017, a_{3}=0.476, a_{4}=$ $0.284, a_{5}=-0.654, a_{6}=0.264, a_{7}=3.06, a_{8}=$ $-3.86, a_{9}=3.64, \Delta$ is the slope of the saturated vapour pressure curve $\left(\mathrm{K} \mathrm{P}_{\mathrm{a}} /{ }^{\circ} \mathrm{C}\right), \gamma$ is the psychrometric constant $\left(\mathrm{K} \mathrm{P}_{\mathrm{a}} /{ }^{\circ} \mathrm{C}\right)$ and $\mathrm{RHD}$ equals to 1 minus RH. VPD is calculated using the saturated water vapour pressure $\left(e_{s}\right)$ minus actual water vapour pressure $(e)$. To calculate $\Delta$ simply, we use the below equation proposed by Richards (1971):

$$
\begin{aligned}
\Delta= & \frac{373.15 e_{s}}{\left(T_{a}+273.15\right)^{2}}\left(13.3185-3.952 T_{r}\right. \\
& \left.-1.9335 T_{r}^{2}-0.5196 T_{r}^{3}\right) \\
e_{s}= & 1013.15 \exp \left(13.3185 T_{r}-1.976 T_{r}^{2}\right. \\
& \left.-0.6645 T_{r}^{3}-0.1299 T_{r}^{4}\right) \\
T_{r}= & 1-373.15 /\left(T_{a}+273.15\right) .
\end{aligned}
$$

Psychrometric constant $\gamma$ can be calculated from:

$$
\begin{aligned}
\gamma & =\frac{C_{p} P_{s}}{0.622 \lambda}, \\
P_{s} & =1013.15 \times 10^{\left(\frac{-z}{18400} \times \frac{T_{a}+273.15}{273}\right)}, \\
\lambda & =4200 \times\left[597-0.6\left(T_{a}+0.15\right)\right],
\end{aligned}
$$

where $z$ is the height above sea level $(\mathrm{m}), C_{p}$ is the isobaric specific heat for dry air and is equal 
to $1012 \mathrm{~J} \mathrm{~kg}^{-1} \mathrm{~K}^{-1}, \lambda$ is the latent heat of vapourization. Considering that estimated ET using LAI will be overestimated when LAI is higher than 3 or 4, using NDVI to replace LAI can effectively correct this issue though NDVI will saturate under dense forests (Wang and Dickinson 2012). In this study, we use the SEMI-PM algorithm driven by daily gridded meteorological datasets to estimate regional ET in the IMARC during 1982-2010.

\subsection{Evaporative wet index}

Following the evaporative drought index (EDI) (Yao et al. 2010), a simple evaporative wet index (EWI) is developed by Zhang et al. (2016) based on the ratio of actual ET and PET, to monitor the terrestrial drought conditions. EWI can be expressed as:

$$
\mathrm{EWI}=1-\mathrm{EDI}=\frac{E T}{P E T} .
$$

In the above equation, higher EWI indicates ample surface soil moisture, lower EWI indicates more severe water stress. The value of EWI varies from 0 to 1 and reflects the changes of surface moisture and $P$, which indicates the surface drought status.

\subsection{Potential ET estimation}

PET refers to the ideal evaporation rate for capturing the response to meteorological variables when soil moisture is unlimited. In this study, the FAO Penman-Monteith (PM) method was used to estimate PET of the IMARC because it is considered as a standard reference method (Allen et al. 1998) and it can be written as:

$$
\begin{aligned}
& \text { PET } \\
& \qquad=\frac{0.408 \Delta\left(R_{n}-G\right)+\gamma\left(900 /\left(T_{a}+273\right)\right) W S\left(e_{s}-e\right)}{\Delta+\gamma(1+0.34 W S)},
\end{aligned}
$$

where $e_{s}$ is the saturated vapour pressure $\left(\mathrm{KP}_{\mathrm{a}}\right)$. $G$ can be calculated using a simple empirical $R_{n^{-}}$ based algorithm based on vegetation fractional cover $\left(f_{c}\right)$ with a fixed empirical coefficient $\left(a_{g}=\right.$ 0.35) (Yao et al. 2013):

$$
\begin{aligned}
G & =a_{g}\left(1-f_{c}\right) R_{n} \\
f_{c} & =\frac{\mathrm{NDVI}-\mathrm{NDVI}_{\min }}{\mathrm{NDVI}_{\max }-\mathrm{NDVI}_{\min }}
\end{aligned}
$$

where $\mathrm{NDVI}_{\min }$ and $\mathrm{NDVI}_{\max }$ are the minimum and maximum normalized difference vegetation index (NDVI) during the study period, which are set as invariant constants: 0.05 and 0.95, respectively (Yao et al. 2013).

\subsection{Trends analysis}

A simple linear regression equation was used to calculate the annual values and trends in variable $y$ (including ET, EWI, PET, PDSI, NDVI and climate factors) against time $x$.

$$
y=a x+b
$$

where $a$ is the linear trend in variables and $b$ is the constant. Student's $t$ test distribution was also used to test the confidence levels ( $p$ values) of the tendencies (Pinker et al. 2005; Zhang et al. 2016).

\section{Results and discussion}

\subsection{Decadal variations in climate factors over the inner Mongolia region}

During 1982-2009, $T_{a}$ in the IMARC from meteorological stations data after removal of the mean annual cycle ( $T_{a}$ anomaly) increased on an average by $0.6^{\circ} \mathrm{C}$ per decade $(p<0.05)$ with global warming (figure 2). Overall, $T_{a}$ in more than $95 \%$ of areas over the IMARC increased from 1982 to 2009 (figure 3). Numerous studies have reported substantial increase in $T_{a}$ in this region (Zhang et al. 2009; Liu et al. 2016). According to the report by the IPCC, the increasing trend in global average $T_{a}$ is $0.074^{\circ} \mathrm{C}$ per decade (IPCC 2007). However, our result is much higher than this value, which indicates that the IMARC has experienced a significant and severe climate change. Similarly, $R_{s}$ in the IMARC from meteorological stations data after removal of the mean annual cycle has a slightly positive trend of $0.2 \mathrm{~W} / \mathrm{m}^{2}$ per decade $(p>0.05)$ (figure 2 ). Southwest and northeast of IMARC experienced a strong positive trend of $R_{s}$ from 1982 to 2009, while central regions of IMARC experienced a strong negative trend during this period (figure 3 ).

$\mathrm{RH}$ had a strong negative trend of $-1.4 \%$ per decade $(p<0.01)$ based on meteorology observations. In contrast, VPD had a strong positive trend of $26.3 \mathrm{~Pa}$ per decade $(p<0.01)$ because the opposite relations between $\mathrm{RH}$ and VPD (figure 2). Almost all regions experienced a strong 

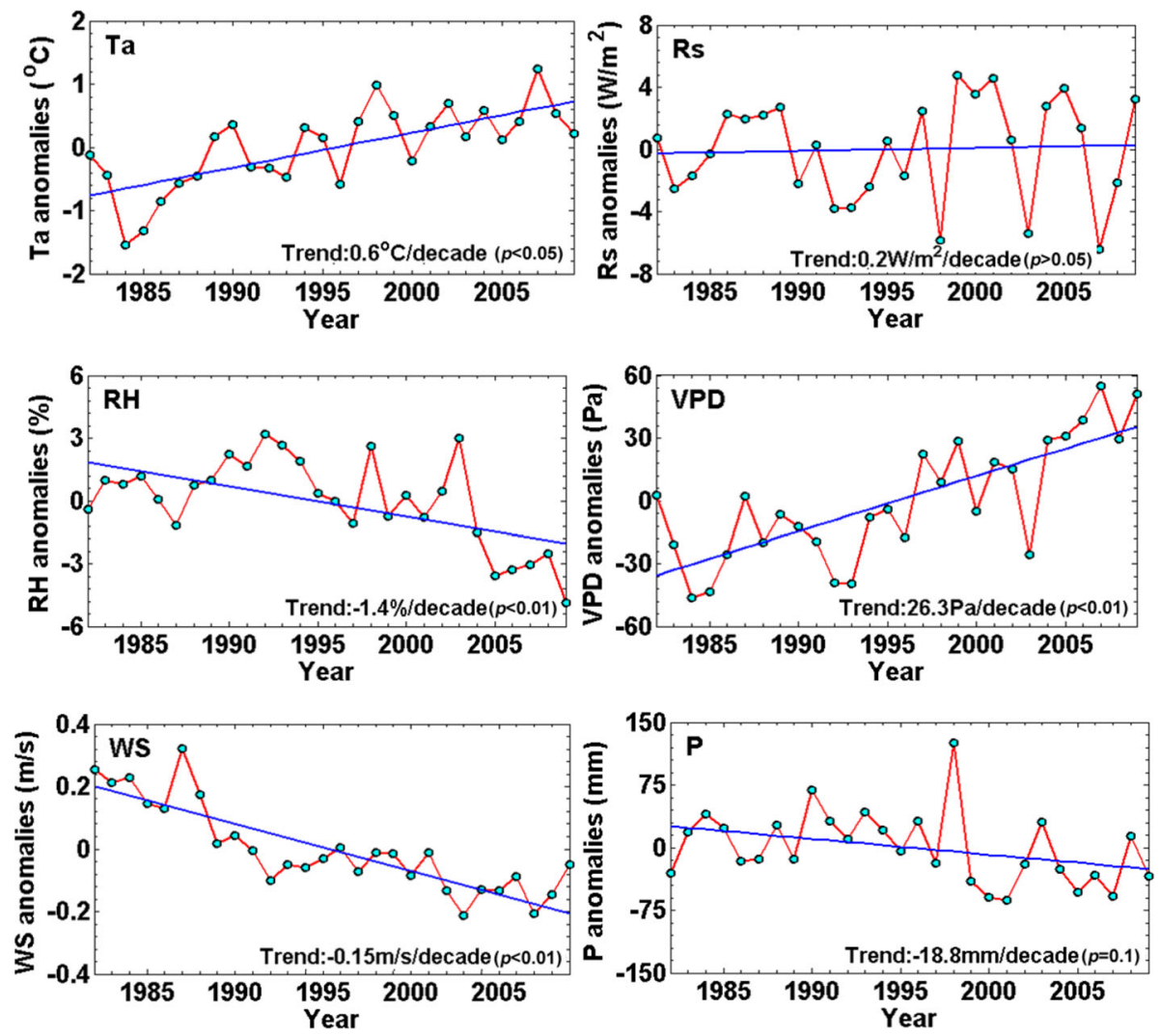

Figure 2. Interannual variability of meteorological variables (Ta, Rs, RH, VPD, WS and P) over the Inner Mongolia of China during 1982-2009.

negative (positive) trend of $\mathrm{RH}$ (VPD) during 1982-2009 (figure 3), which is consistent with previous studies (Guo et al. 2014; Xia et al. 2014). WS had a strong negative trend of $-0.15 \mathrm{~m} / \mathrm{s}$ per decade $(p<0.01)$ based on meteorology observations (figure 2). More than 93\% regions of the IMARC experienced a negative trend of WS during 1982-2009 (figure 3). Similarly, $P$ also had a negative trend of $-18.8 \mathrm{~mm}$ per decade $(p=0.1)$ based on meteorology observations (figure 2). Northeast regions of the IMARC experienced a strong negative trend of $P$ from 1982 to 2009, while southwest regions experienced a weak positive trend of $P$ during this period (figure 3 ), which is similar to the previously documented increasing trend in $P$ over the desert and barren land over western region of the Dryland East Asia, as reported by Xia et al. (2014).

\subsection{Spatial and decadal variation in ET and EWI}

\subsubsection{Evaluation of the ET algorithm}

Figure 4 shows the biases, the root-mean-square error (RMSE), and the square of the correlation coefficients $\left(R^{2}\right)$ for comparison between the ground-measured and estimated daily ET using daily gridded meteorological data and GIMMIS NDVI product at the four sites (XFS, XLG, DSG and DLG). We can notice that the bias for XFS, XLG, DSG and DLG are 0.27, 0.14, 0.54 and $0.19 \mathrm{~mm}$, respectively. The $R^{2}$ for XFS, XLG, DSG and DLG are $0.61,0.55,0.45$ and 0.84 , respectively. The RMSE for the four sites are $<0.78 \mathrm{~mm}$. The positive bias may be partially due to the unclosed energy balance problem in the eddy covariance datasets and the limitations of the SEMI-PM algorithm (Wang et al. 2010; Yao et al. 2014). However, at the DLG site, the algorithm overestimates ET. Perhaps complex terrain and instrument calibration contribute to the large bias at the DLG site. Jiang et al. (2004) documented that a reasonable upper limit for the accuracy of estimating ET using satellite data is about 20\%. Seguin et al. (1999) suggested that the required ET retrieval accuracy varies according to the application, but is typically $15-30 \%$. The accuracy of our validation meets this requirement.

Although the ground-based eddy covariance data for 2-3 years prohibits the validation of long-term ET estimates, Wang et al. (2010) verified that the 

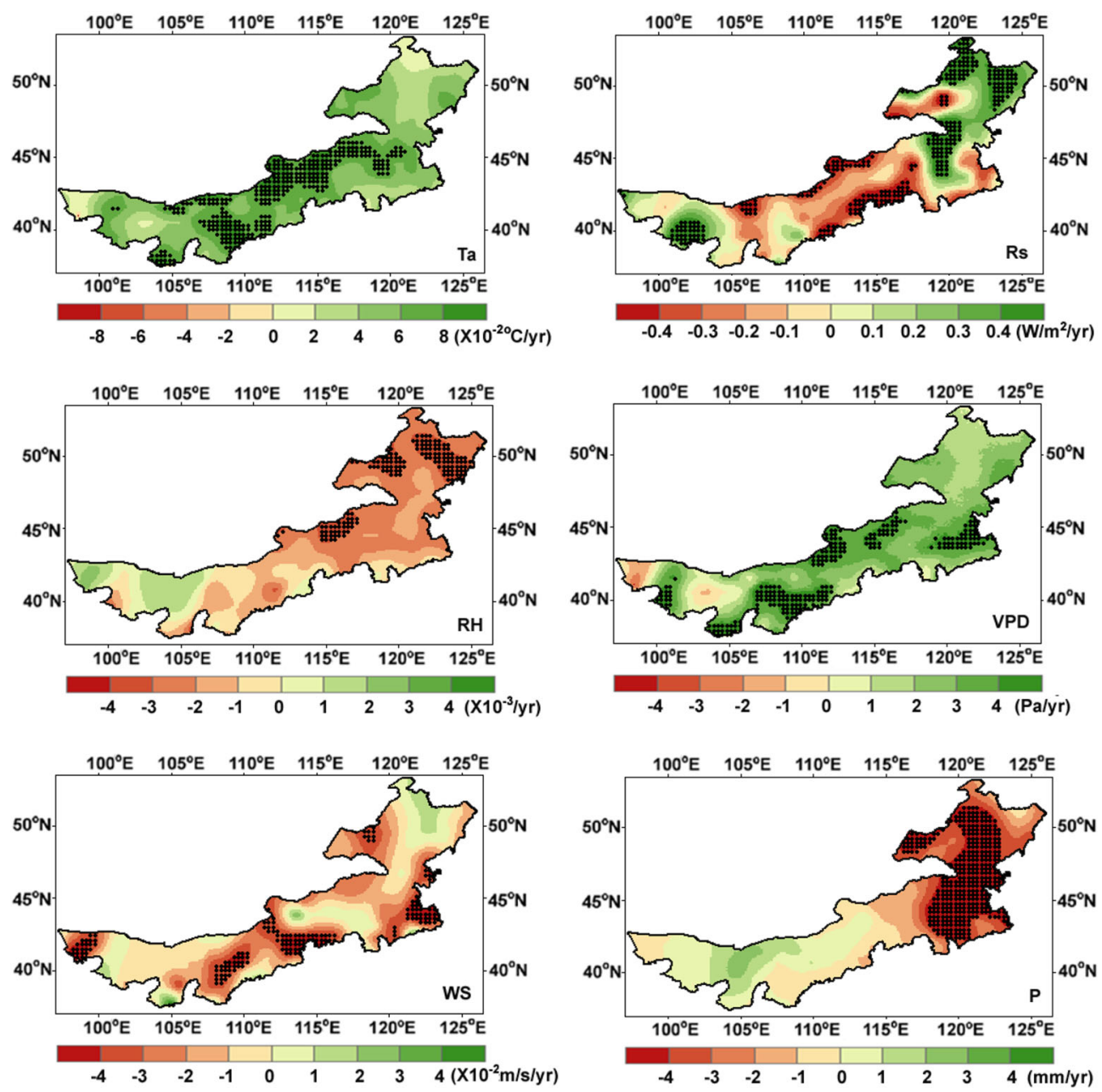

Figure 3. Maps of the linear trend in meteorological variables (Ta, Rs, RH, VPD, WS and P) over the Inner Mongolia region of China from 1982 to 2009. The black solid dots refer to grids with $95 \%$ confidence.

SEMI-PM algorithm is satisfactory for reproducing inter-annual variability at sites with 5 years of global FLUXNET eddy covariance data. However, ET has still existed with large uncertainty and the possible sources of uncertainty in ET estimation may be attributed to: (1) the errors in gridded data inputs (e.g., errors of $\pm 20 \mathrm{~W} / \mathrm{m}^{2}$ in $\left.R_{s}\right)$; (2) the biases of the ground-measured $E T$, where the typical error of is about 20\% (Babamaaji and Lee 2014; Hollinger and Richardson 2005); (3) the energy imbalance issue of the eddy covariance method (Twine et al. 2000); (4) simulation errors in the SEMI-PM algorithm (Wang et al. 2010); and (5) the spatial scale mismatch between the footprint and gridded datasets (including meteorological datasets and GIMMIS-NDVI dataset). The observed ET footprint only represents the vapour evaporation over about a few hundred meters in the vertical and horizontal directions (Twine et al. 2000). However, the gridded datasets with coarse spatial resolution $(10 \mathrm{~km})$ may not capture the ET information measured at the scale of footprints (Yao et al. 2014). Therefore, a series of errors may be introduced in the ET estimates.

We also compared the average annual estimated ET during 2001-2009 with the corresponding MOD16 ET product. Figure 5(a and b) shows similar spatial distribution patterns in both maps, though the ET over the central eastern areas of the IMARC exhibits small differences and the MOD16 ET product has no ET value over the western barren land areas. One can see that the bias of the average annual estimated ET during 2001-2009 that deviates from the MOD16 ET is $-2.71 \mathrm{~mm}$, the RMSE is $37.25 \mathrm{~mm}$ and the $R^{2}$ is 0.50 (figure $5 \mathrm{c}$ ). This small discrepancy may be caused by the errors of input data and different structures of the algorithms. The input data for MODIS ET product is the 

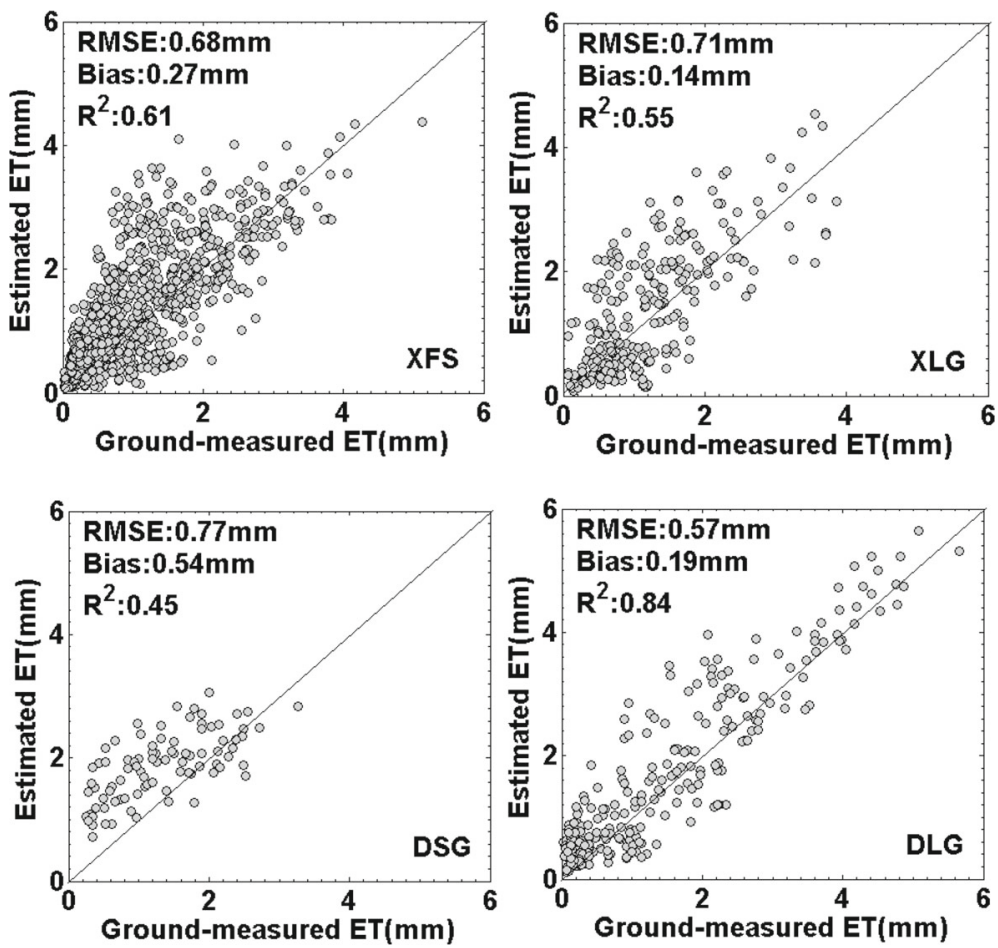

Figure 4. Validation of the estimated daily evapotranspiration (ET) using the semi-empirical Penman ET algorithm for four sites.

Modern Era Retrospective Analysis for Research and Applications (MERRA) meteorological data. Previous studies found that substantial errors for MERRA data when compared to ground measurements (Zhao et al. 2006). MODIS ET product is generated based on the satellite-based PenmanMonteith (PM) method. Recent studies reveal that although PM method can be widely used across a range of land cover and climate conditions, there is a significant underestimation of evaporation in croplands or in deciduous forests (Ershadi et al. 2014). Fortunately, there is a relatively good agreement between the two independent datasets in this study, which indicates that the SEMI-PM algorithm provides reliable information for $E T$ estimation in this region.

\subsubsection{Mapping terrestrial ET and drought}

Figure 6 shows the spatial patterns of multiyear (1982-2009) mean annual ET, PET, EWI and PDSI over the IMARC from all gridded datasets. They show the strong regional variations corresponding to the climate patterns. ET, EWI and PDSI have increased from the southwest to the northeast. In contrast, PET has the opposite spatial patterns with high values in southwest and low values in northeast. Generally, PDSI characterizes surface drought by combining $P$ and soil moisture (SM) while EWI reflects surface drought by combining $R_{n}, T_{a}$, WS, RH and NDVI, without requiring information regarding antecedent $P$. IMARC belongs to arid and semiarid region, in which water supply is mainly determined by the variation in both $P$ and SM. Therefore, grass and other vegetation are affected by $P$ to sustain long term $E T$ because vegetative roots can extract moisture from deeper soil layers (Anderson et al. 2007). These spatial distribution maps supply an important background and physical interpretation for energy, water and climate change in arid and semiarid regions of China.

Figure 7(a) shows the seasonal cycle of the spatially averaged and integrated monthly ET for four land cover types from January 1982 to December 2009. Forest has the largest seasonal variability in spatial averaged ET, followed by crop and grass, and bare land has the least variability. The seasonal cycle of the spatially averaged and integrated monthly PET also showed clear dependence on biome (figure $7 \mathrm{~b}$ ). Taken separately, bare land has the highest seasonal variability in monthly PET, followed by grass and crop and forest has the least variability. Both spatially averaged ET and PET 

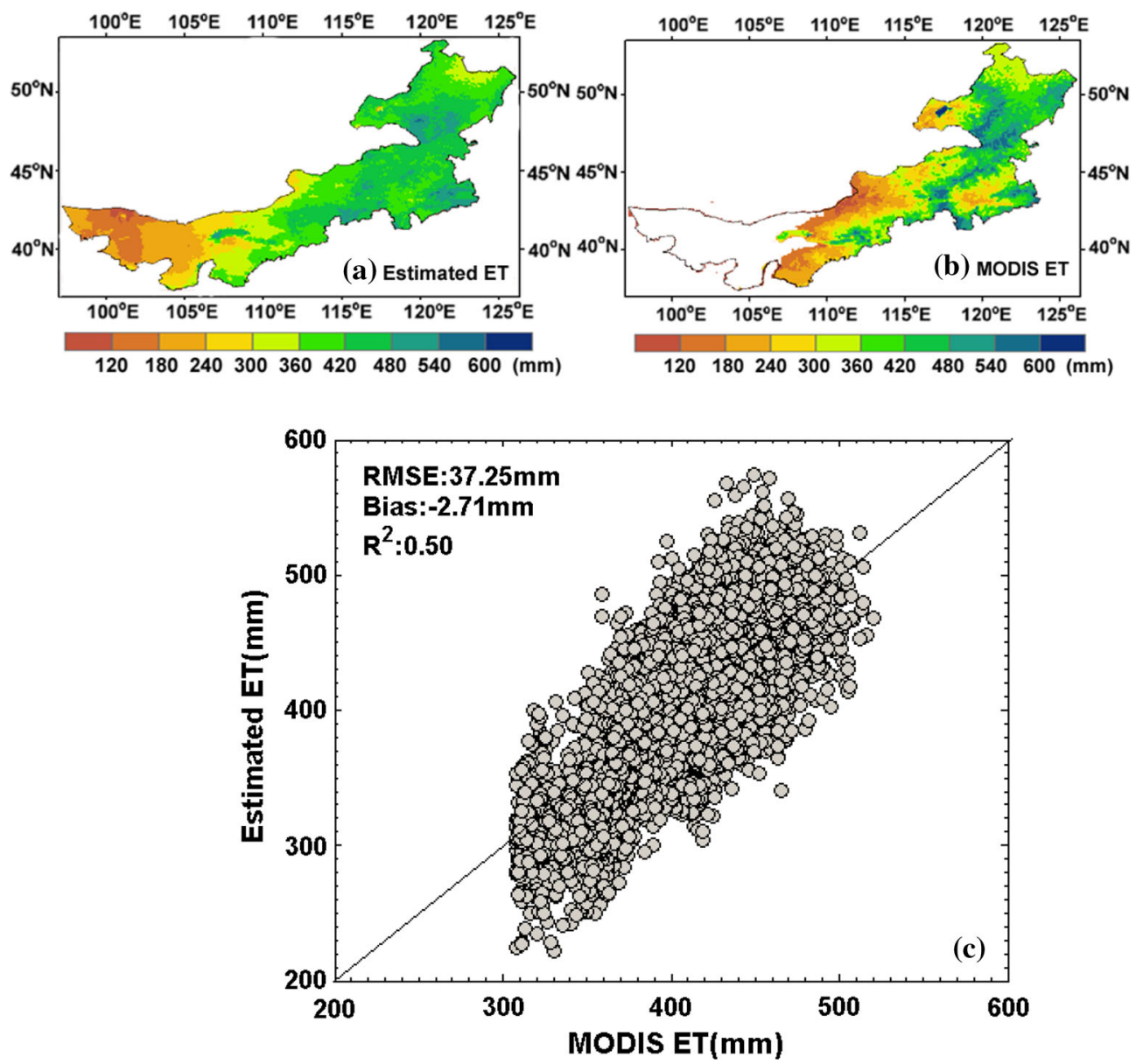

Figure 5. (a) The spatial distribution of the estimated mean annual ET from 2001 to 2009 in this study; (b) spatial distribution of the corresponding MOD16 ET; and (c) scatter plots of the estimated mean annual ET from 2001 to 2009 and the corresponding MOD16 ET.
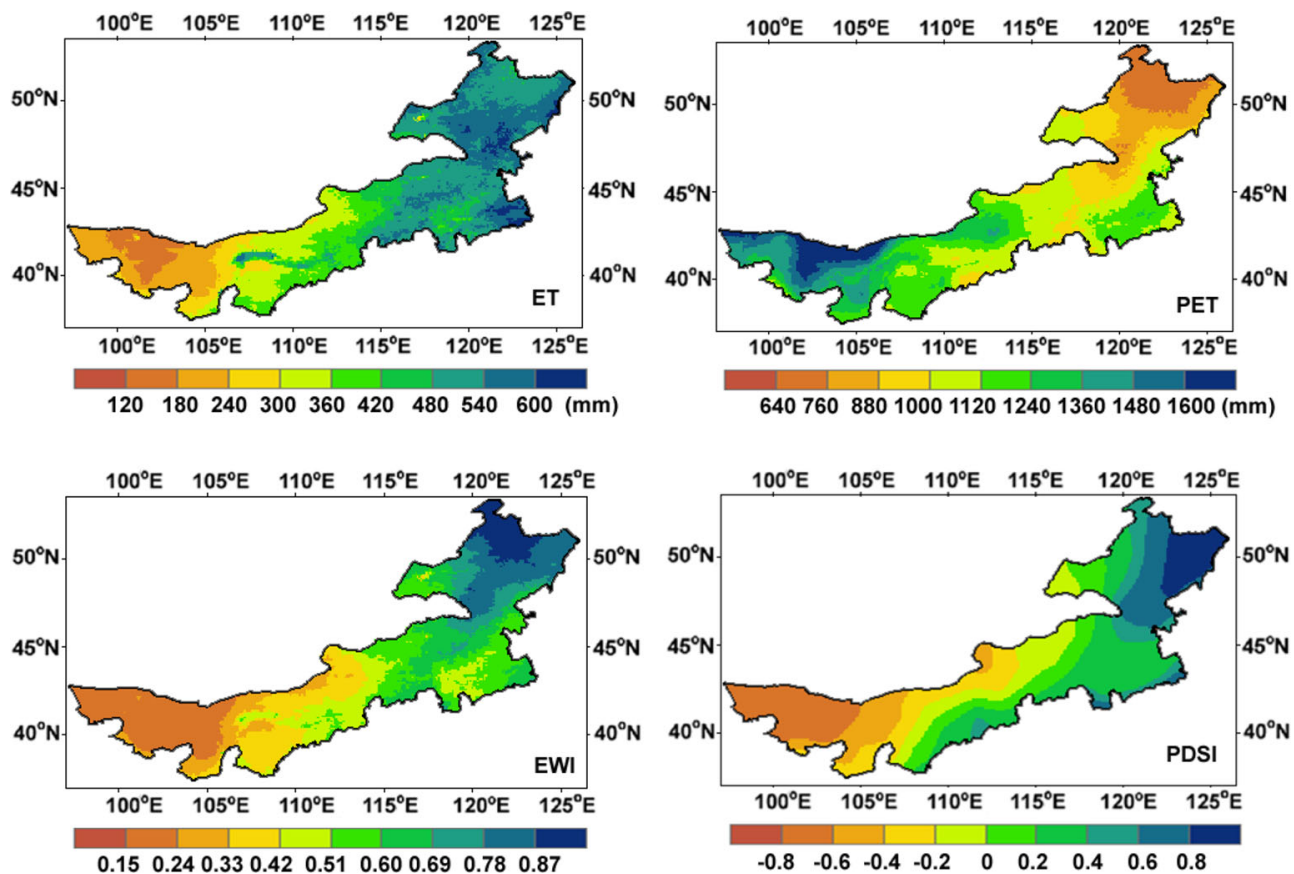

Figure 6. Maps of multi-year (1982-2009) mean annual ET, PET, EWI and PDSI over the Inner Mongolia region of China. 

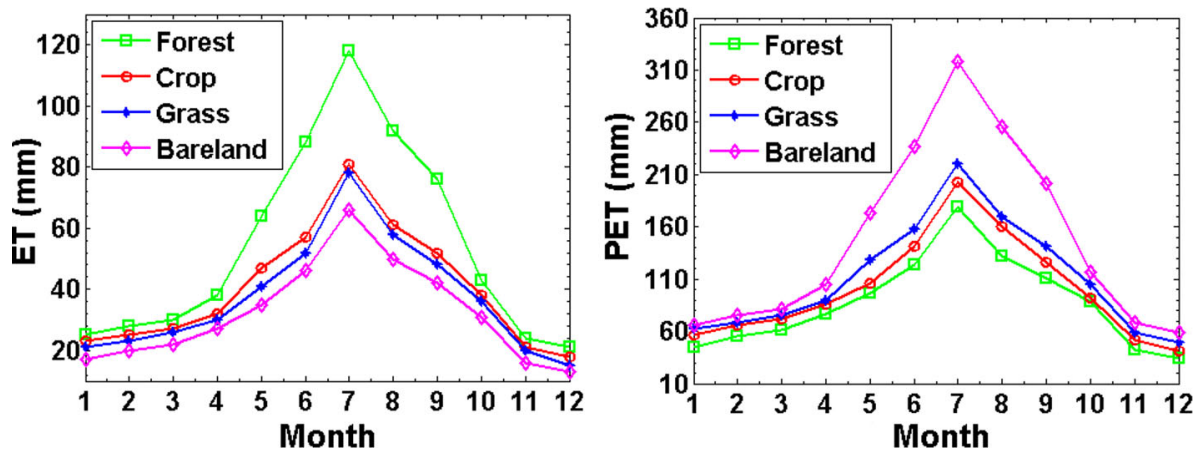

Figure 7. Seasonal cycle of the spatially averaged and integrated monthly ET and PET for four land cover types from January 1982 to December 2009.

show seasonal and inter-annual variability for each land cover type.

Although some uncertainties are present, the ET magnitudes and spatial pattern of ET in the IMARC is generally consistent with previous reports (Yang and Zhou 2011; Xia et al. 2014). Xia et al. (2014) found the increasing patterns from the southwest to the northeast using the Modern-Era Retrospective Analysis for Research and Applications (MERRA) data. Yang and Zhou (2011) reported that seasonal variation in ET followed closely the variation in soil water content (SWC) and is consistent with the variation in PDSI. Although different algorithm parameterizations and inputs have an impact on their simulation by partitioning the surface energy flux in a different manner (Robock et al. 2003), the spatial patterns of the estimated ET and EWI is acceptable for assessing the surface water budget and drought conditions at regional scales.

To analyze the spatial pattern in both anomalies of EWI $(\Delta \mathrm{EWI})$ and PDSI $(\Delta \mathrm{PDSI})$ during 1982-2009, we mapped the annual EWI deviations $(\triangle \mathrm{EWI})$ and PDSI deviations $(\Delta \mathrm{PDSI})$ for 1998 (wet year) and 2000 (dry year). In dry year of 1998 , both $\triangle$ EWI and $\triangle$ PDSI show that the western and central regions were wetter (figure 8), a result which is consistent with those of previous studies (Dai et al. 2004; Zhao and Running 2010). El Niño event occurred in 1998 and heavy $P$ in north regions of China lead to wet surface. The $\Delta$ EWI map reveals that during this year, there was an extreme drought stretching across Northeast regions of the IMARC, but the $\triangle$ PDSI map shows an opposite trend. These discrepancies between the $\triangle$ EWI and $\triangle$ PDSI map may be caused by the interpolation errors of the coarse spatial resolution of PDSI product and the errors of input data of the EWI. In contrast to 1998, both indices for 2000 show the western and central eastern regions became dryer. El Niño event extends to 2000 and sparse precipitation led to large drought of mainland China (Brogaard et al. 2005). However, for both indices, there are opposite trends in northeast regions of the IMARC. Perhaps the errors of the interpolation of the sparse meteorological variables observed points across the IMARC led to their differences.

\subsubsection{Spatial and decadal variation from 1982 to 2009}

The estimated ET, PET, EWI, PDSI and NDVI in the IMARC from the gridded reanalysis meteorological datasets and GIMMIS-NDVI product after removal of the mean annual cycle show that NDVI has decreased on an average by $0.15 \%$ per decade $(p<0.05)$ during the study period. In contrast, $P E T$ has increased on an average by $16.1 \mathrm{~mm}$ per decade $(p=0.09)$ (figure 9$)$. On the whole, ET, EWI and PDSI have decreased on an average by $4.8 \mathrm{~mm} /$ decade $(p=0.10)$, $1.1 \% /$ decade $(p=0.08)$ and $0.8 \% /$ decade $(p=$ $0.10)$, respectively over the entire IMARC during 1982-2009 (figure 9). However, these values (ET, EWI and PDSI) increased by approximately $0.7 \mathrm{~mm} /$ decade, $0.2 \% /$ decade and $0.1 \% /$ decade, respectively, with no significant change from 1982 to 1998 due to a large El Niño event. After that, they decline by approximately $10.2 \mathrm{~mm} /$ decade, $2.8 \% /$ decade and $1.9 \%$ /decade (significant at the $99 \%$ level), respectively. Figure 9 also shows the strong coherence between 1982 and 2009 EWI trends derived from satellite data, and trends in the independent gridded PDSI over the IMARC in which surface moisture is expected to affect 

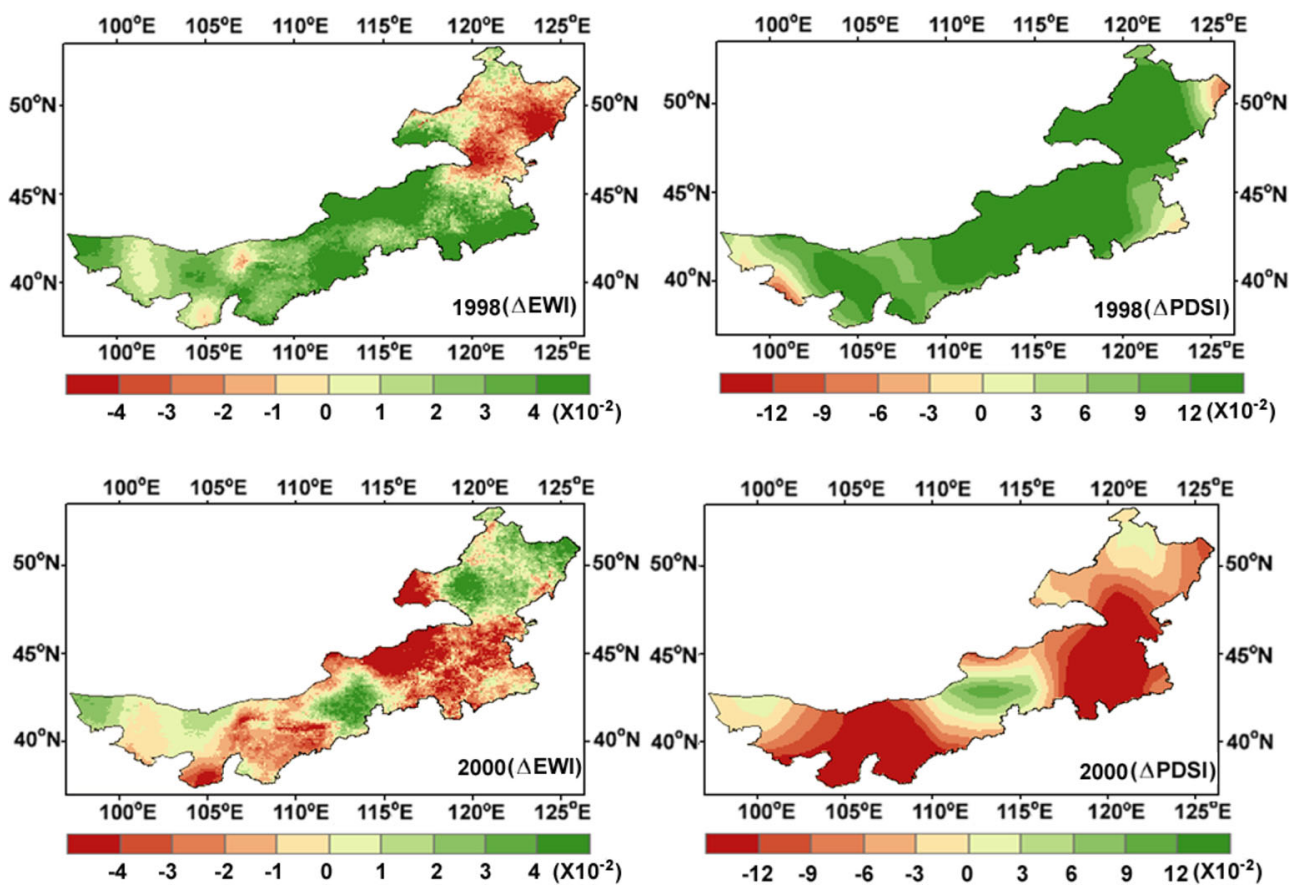

Figure 8. An example of annual composites of anomalies of EWI $(\Delta \mathrm{EWI})$ compared with anomalies in the PDSI $(\Delta \mathrm{PDSI})$ for 1998 (wet year) and 2000 (dry year).
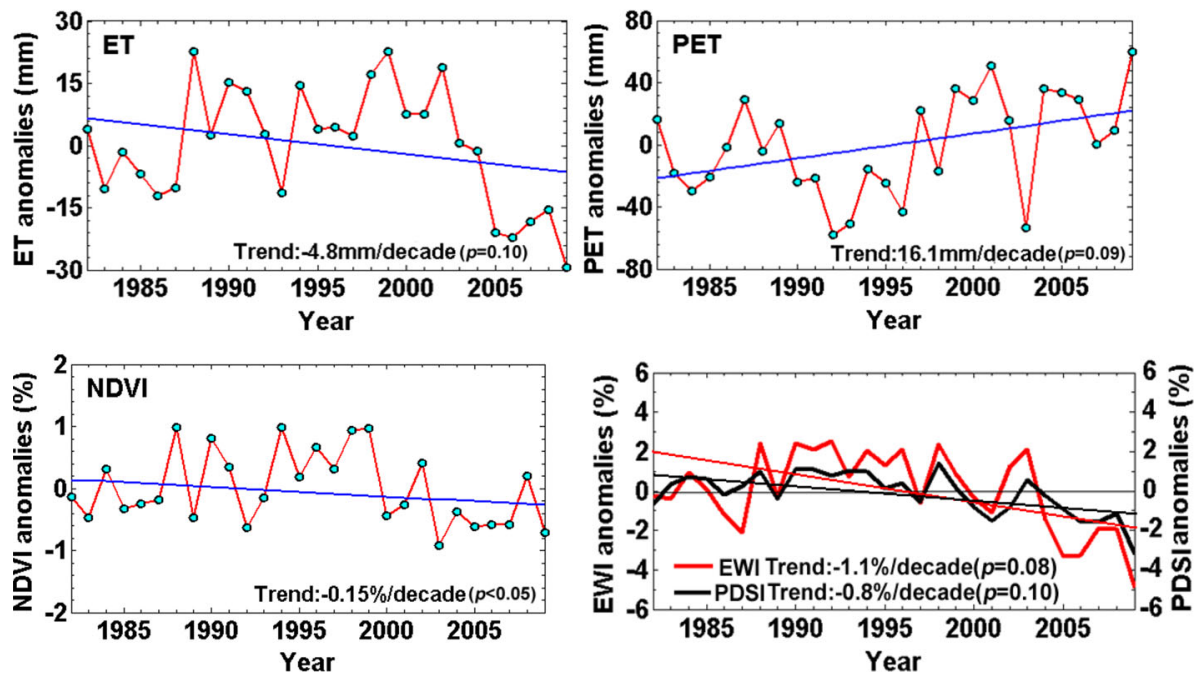

Figure 9. Interannual variability of ET, PET, NDVI, EWI and PDSI over the Inner Mongolia of China during $1982-2009$.

terrestrial ET. The result is similar to the previously documented data that the annual terrestrial ET in the IMARC has also declined since 1992 and may be attributed to the limitation of severe drought (Yao et al. 2013; Xia et al. 2014).

Figure 10 shows the spatial pattern of the trends in the terrestrial ET, PET, EWI, PDSI and NDVI over the IMARC during 1982-2009. We notice that a widely significant decreasing trend in ET appears from 1982 to 2009 in central regions of the IMARC. However, a widely increasing trend in PET appears for the study period in both central and northeast regions of the IMARC due to the high atmospheric evaporative demand (Zhang et al. 2016). Similarly, Yao et al. (2014) reported that the PET substantially increased in arid areas while the few changes in the Qinghai-Tibet region may be caused by increased precipitation in the area during the study period. The largest decreasing EWI, PDSI and NDVI trends appear in both central and northeast regions of the IMARC. The similar trends of both indices reflect the widely severe drought in this region, which is consistent with the findings 

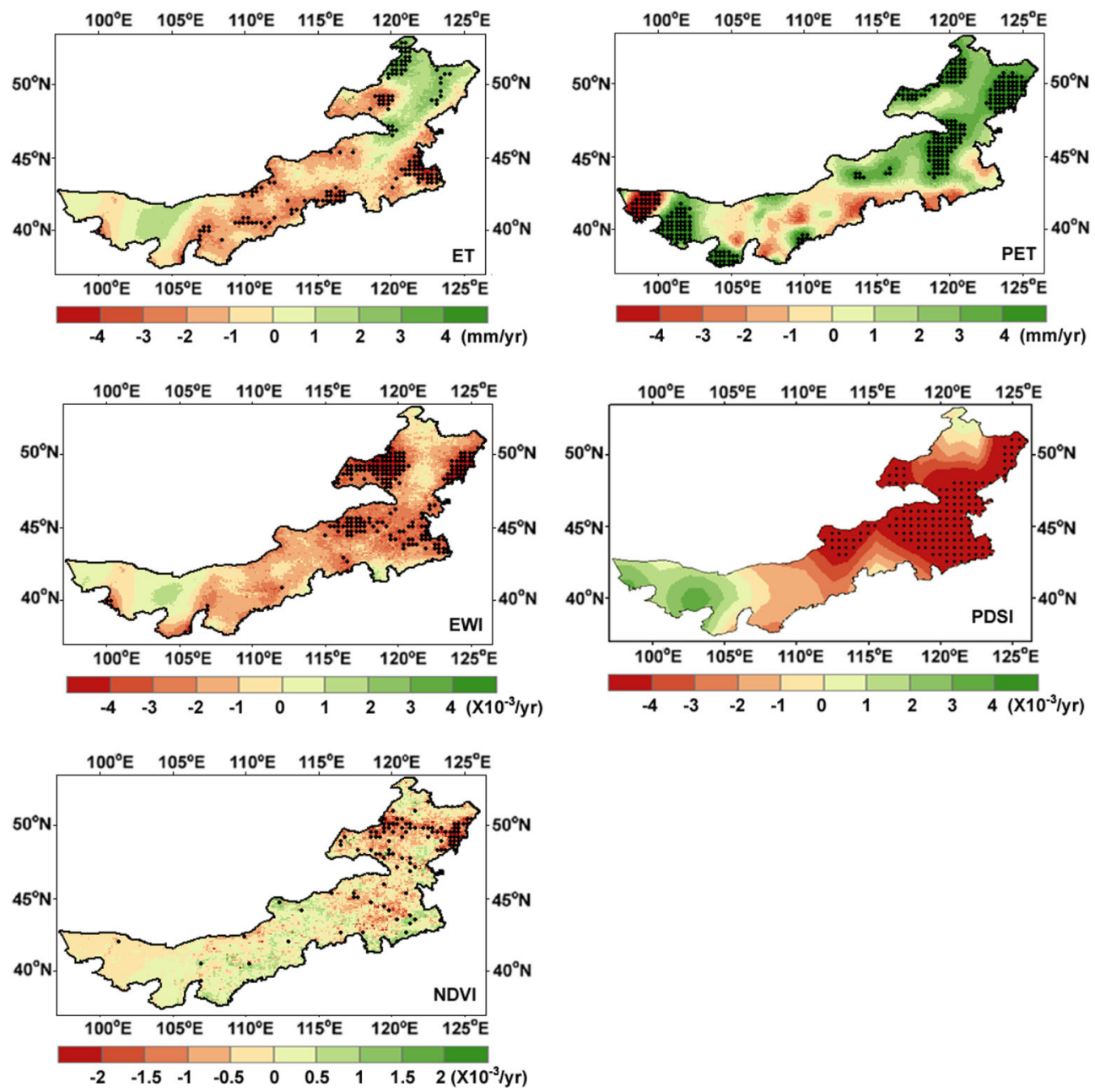

Figure 10. Maps of the linear trend in ET, PET, EWI, PDSI and NDVI over the Inner Mongolia region of China from 1982 to 2009. The black solid dots refer to grids with $95 \%$ confidence.

of Yao et al. (2013). In theory, EWI trends are more consistent with PDSI trends because EWI is a better indicator of surface SM supply of ET and PDSI contains the $P$ and SM information.

According to the definition of EWI, the change of ET contributes to the long-term variation of EWI. The variations of EWI over most regions of XUARC (Xinjiang Uighur Autonomous Region of China) are almost consistent with $E T$ variations. EWI characterizes the surface dryness conditions and is also consistent with the variations in NDVI. This may be explained by the fact that the drying trend occurring over the IMARC can exert profound impacts on a variety of terrestrial ecosystem structures and functions including the carbon and water cycle, plant distribution and vegetation growth (John et al. 2009). Zhang et al. (2009) reported drought-induced reductions in vegetation net primary productivity (NPP) over northern
Mongolia. Xia et al. (2014) also documented that the changes in ET and water balance over the Dryland East Asia are spatially complex. These will facilitate drought monitoring at field, regional and global scales, which will be valuable for drought assessment induced crop yield loss.

\subsection{Correlations between ET and meteorological variables}

Both $T_{a}$ and $R_{s}$ showed strong positive correlations with ET over the northeast region of the IMARC, while they showed strong negative correlations with ET over the central region of the IMARC because the contributions of the temperature and energy to ET differ greatly in different regions (figure 11). Additionally, the coefficients between $E T$ and $\mathrm{RH}$ are positive over the southwest and central regions of the IMARC and are negative 

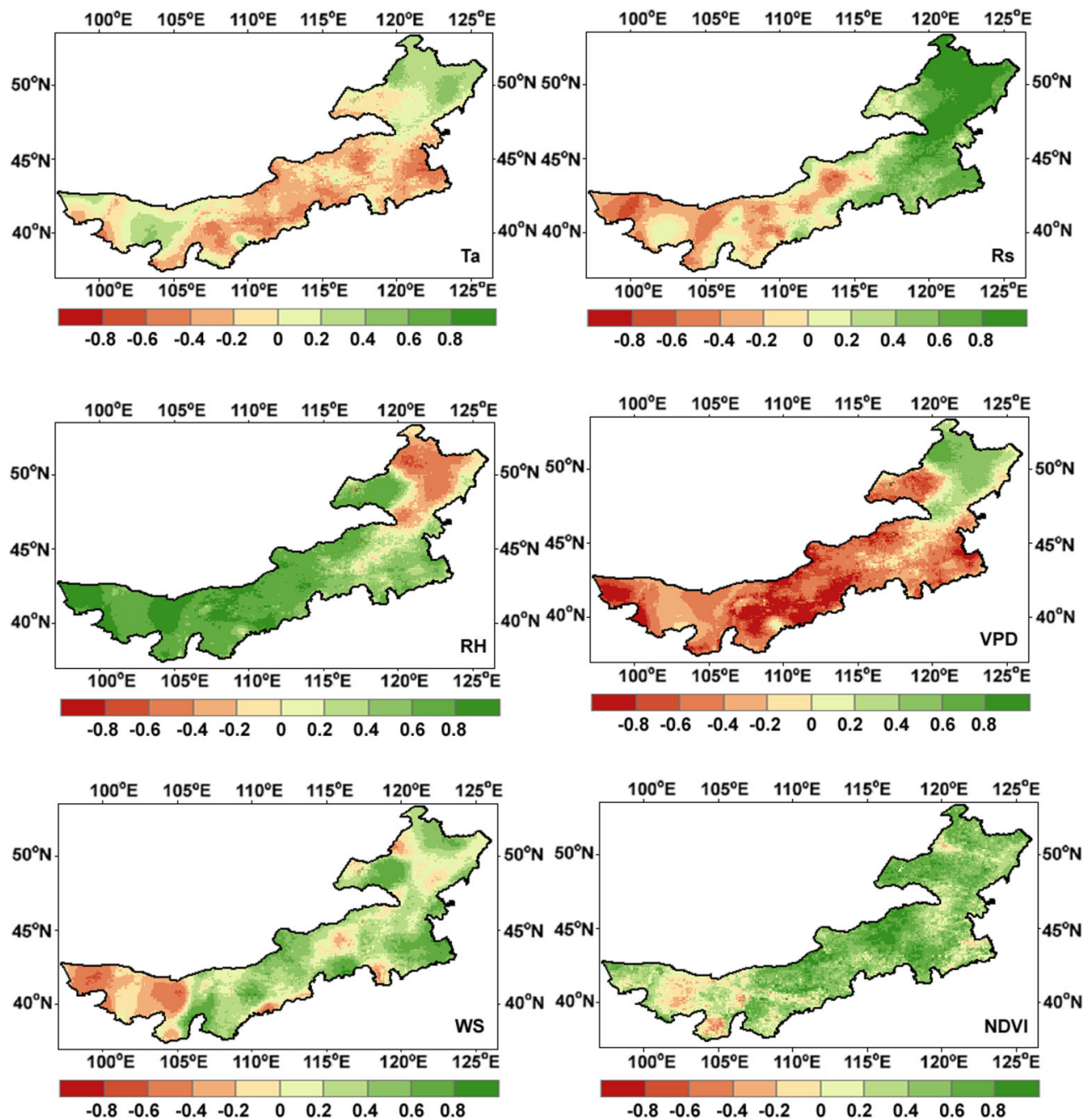

Figure 11. Maps of the correlation coefficient between annual $E T$ and $T_{a}, R_{s}, R H$, VPD, WS and NDVI, respectively.

over the northeast region of the IMARC. This can be explained that $\mathrm{RH}$, as an indicator of the surface moisture, controls ET of arid and semi-arid regions. In contrast, there are opposite spatial patterns of the correlations between ET and VPD due to the negative correlations between RH and VPD (figure 11). Both NDVI and WS also showed strong positive correlations with ET over majority of the central and northeast Inner Mongolia except the region near the Gobi desert (figure 11) due to the effects of supply water of vegetation and vapour transferring by air motion.

Regional climate change has produced substantial effects on terrestrial ET and surface drought by altering environmental controlling factors. However, there are different controlling factors for $E T$ in different climate zones (Wang and Dickinson 2012). In high-latitude ecosystems of northeast region of the IMARC, both $T_{a}$ and $R_{s}$ are the most important parameters in determining ET in these ecosystems (Nemani et al. 2003). ET in this region is also related to VPD (Kelliher et al. 1997). Forests in this region is little affected by surface drought because near-surface soil water was depleted and the water table remained in the root zone (Krishnan et al. 2006). However, in semi-arid and arid areas of the central and southwest regions of the IMARC, Both RH and NDVI are the most important factors controlling annual variation of ET because they are the primary surface moisture factors, which determine the ET (Wang and Dickinson 2012). Recent studies found that soil moisture in north-central and northeastern China had significant downward trends, implying that northern China has become slightly drier in terms of soil moisture to influence the variation in ET (Cong et al. 2009; Yao et al. 2016). Our study also illustrated the contributions of WS to ET, 
which is consistent with the previous studies that reported WS as an aerodynamic controlling variable for atmospheric evaporative demand during the ET process and contributes to long-term ET variations (McVicar et al. 2012).

\section{Conclusion}

The goal of the study was to present a strategy for estimating terrestrial ET and assessing surface drought using a semi-empirical Penman ET (SEMI-PM) algorithm proposed by Wang et al. (2010) over Inner Mongolia Autonomous Region of China (IMARC). We also used meteorological data and satellite data to analyze the spatiotemporal variation in ET and EWI during 1982-2009. The results demonstrated that SEMI-PM algorithm has a good performance in estimating $E T$ and assessing regional drought monitoring over the IMARC.

In this paper, we produced the daily and annual ET and EWI from 1982 to 2009 using the SEMIPM algorithm driven by daily gridded meteorological data and GIMMIS-NDVI product. Using the ET measurements of the four eddy covariance sites, our validation showed the SEMI-PM algorithm provided the reliable ET estimations which were useful to detect regional ET and surface drought conditions. Over the entire study area, both ET and EWI have decreased during 1982-2009. Especially, a widely significant decreasing trend in ET appears from 1982 to 2009 in central regions of the IMARC. Importantly, the patterns of monthly EWI anomalies have a good spatial and temporal correlation with the Palmer Drought Severity Index (PDSI) anomalies from 1982 to 2009. In high-latitude ecosystems of northeast region of the IMARC, both $T_{a}$ and $R_{s}$ are the most important parameters in determining $E T$ in these ecosystems. However, in semiarid and arid areas of the central and southwest regions of the IMARC, Both $\mathrm{RH}$ and NDVI are the most important factors controlling annual variation of ET.

\section{Acknowledgements}

The authors would like to extend their thanks to China Meteorological Administration (CMA) for providing ground-measured meteorological data. The authors would also like to thank Dr Shaomin Liu from Beijing Normal University, Dr Guangsheng Zhou and Dr Qibing Wang from the Institute of Botany, Chinese Academy of Sciences, for providing ground-measured data. Other Eddy covariance measured data for two flux tower sites in this study was downloaded from Chinaflux network (http://159.226.111.42/pingtai/LoginRe/ opendata.jsp) and the Coordinated Enhanced Observation Project (CEOP) in arid and semiarid regions of northern China (http://observation. tea.ac.cn/). MODIS land cover satellite product was obtained online (http://reverb.echo.nasa.gov/ reverb). MOD16 ET product was obtained online (ftp://ftp.ntsg.umt.edu/pub/MODIS/NTSG_Prod ucts/MOD16/MOD16A2.105_MERRAGMAO/).

PDSI product was obtained online (http://www. cgd.ucar.edu/cas/catalog/climind/pdsi.html). This work was also partially supported by the National Key Research and Development Program of China (No. 2016YFB0501404) and the Natural Science Fund of China (41671331).

\section{References}

Allen R, Pereira L, Raes D and Smith M 1998 Crop evapotranspiration guidelines for computing crop water requirements; FAO Irrigation and drainage paper, 300p.

Anderson M, Norman J, Mecikalski J, Otkin J and Kustas W 2007 A climatological study of evapotranspiration and moisture stress across the continental United States based on thermal remote sensing; J. Geophys. Res. 112 D10117.

Babamaaji R and Lee J 2014 Land use/land cover classification of the vicinity of Lake Chad using NigeriaSat-1 and Landsat data; Environ. Earth Sci. 71 4309-4317.

Brogaard S, Runnström M and Seaquist J 2005 Primary production of Inner Mongolia, China, between 1982 and 1999 estimated by a satellite data-driven light use efficiency model; Global Planet. Change 45 313-332.

Cao Y, Nan Z and Cheng G 2015 GRACE gravity satellite observations of terrestrial water storage changes for drought characterization in the arid land of northwestern China; Rem. Sens. 7 1021-1047.

Chen S, Chen J, Lin G, Zhang W and Miao H et al. 2009 Energy balance and partition in Inner Mongolia steppe ecosystems with different land use types; Agric. For. Meteorol. 149 1800-1809.

Cong Z, Yang D, Gao B, Yan H and Hu H 2009 Hydrological trend analysis in the Yellow River basin using a distributed hydrological model; Water Resour. Res. 45 W00A13.

Dai A, Trenberth K and Qian T 2004 A global dataset of palmer drought severity index for 1870-2002: Relationship with soil moisture and effects of surface warming; J. Hydrometeorol. 5 1117-1130.

Ershadi A, McCabe M, Evans J, Chaney N and Wood E 2014 Multi-site evaluation of terrestrial evaporation models using FLUXNET data; Agric. For. Meteorol. 187 46-61.

Guo L, Wu S, Zhao D, Yin Y and Leng G et al. 2014 NDVIbased vegetation change in Inner Mongolia from 1982 to 2006 and its relationship to climate at the biome scale; Adv. Meteorol. 692068. 
Hollinger D and Richardson A 2005 Uncertainty in eddy covariance measurements and its application to physiological models; Tree Physiol. 25 873-885.

IPCC 2007 Climate Change 2007: Synthesis Report: Summary for Policymakers, available at: http://www.ipcc.ch/ publications_and_data/ar4/syr/en/spms1.html.

Jiang H, Liu S, Sun P, An S and Zhou G et al. 2004 The influence of vegetation type on the hydrological process at the landscape scale; Can. J. Rem. Sens. $30743-763$.

John R, Chen J, Lu N and Wilske B 2009 Land cover/land use change in semiarid Inner Mongolia: 1992-2004; Environ. Res. Lett. 4045010.

Jung M, Reichstein M, Ciais P, Seneviratne S and Sheffield J et al. 2010 Recent decline in the global land evapotranspiration trend due to limited moisture supply; Nature 467 951-954.

Jung M, Reichstein M, Margolis H, Cescatti A and Richardson A et al. 2011 Global patterns of land-atmosphere fluxes of carbon dioxide, latent heat, and sensible heat derived from eddy covariance, satellite, and meteorological observations; J. Geophys. Res. 116 G00J07.

Kelliher F, Hollinger D, Schulze E, Vygodskaya N and Byers J et al. 1997 Evaporation from an eastern Siberian larch forest; Agric. For. Meteorol. 85 135-147.

Krishnan P, Black T, Grant N, Barr A and Hogg E et al. 2006 Impact of changing soil moisture distribution on net ecosystem productivity of a boreal aspen forest during and following drought; Agric. For. Meteorol. 139 208-223.

Li X, Liang S, Yuan W, Yu G and Cheng X et al. 2014 Estimation of evapotranspiration over the terrestrial ecosystems in China; Ecohydrology 7 139-149.

Liu S, Kang W and Wang T 2016 Drought variability in Inner Mongolia of northern China during 1960-2013 based on standardized precipitation evapotranspiration index; Environ. Earth Sci. $\mathbf{7 5} 145$.

McVicar T, Roderick M, Donohue R, Li L and Van Niel $\mathrm{T}$ et al. 2012 Global review and synthesis of trends in observed terrestrial near-surface wind speeds: Implications for evaporation; J. Hydrol. 416-417 182-205.

$\mathrm{Mu}$ Q, Zhao M and Running S 2011 Improvements to a MODIS global terrestrial evapotranspiration algorithm; Rem. Sens. Environ. 115 1781-1800.

Nemani R, Keeling C, Hashimoto H, Jolly W and Piper S et al. 2003 Climate-driven increases in global terrestrial net primary production from 1982 to 1999; Science $\mathbf{3 0 0}$ 1560-1563.

Pinker R, Zhang B and Dutton E 2005 Do satellites detect trends in surface solar radiation?; Science 308 850-854.

Priestley C and Taylor R 1972 On the assessment of surface heat flux and evaporation using large-scale parameters; Mon. Wea. Rev. 100 81-92.

Robock A, Luo L, Wood E, Wen F and Mitchell K et al. 2003 Evaluation of the North American land data assimilation system over the southern Great Plains during the warm season; J. Geophys. Res. 108(D22) 8846.

Richards J 1971 Simple expression for the saturation vapor pressure of water in the range $-50^{\circ}$ to $140^{\circ}$; Bri. J. Appl. Phys. 4 115-118.

Seguin B, Becker F, Phulpin T, Gu X and Guyot G et al. 1999 IRSUTE: A mini-satellite project for land surface heat flux estimation from field to regional scale; Rem. Sens. Environ. 68 357-369.
Shi Y, Shen Y, Kang E, Li D and Ding Y et al. 2007 Recent and future climate change in Northwest China; Clim. Change 80 379-393.

Skidmore E, Jacobs H and Powers W 1969 Potential evapotranspiration as influenced by wind; Agron. J. 61 543-546.

Tucker C, Pinzon J, Brown M, Slayback D and Pak E et al. 2005 An extended AVHRR 8-km NDVI dataset compatible with MODIS and SPOT vegetation NDVI data; Int. J. Rem. Sens. 26 4485-4498.

Twine T, Kustas W, Norman J, Cook D and Houser P et al. 2000 Correcting eddy- covariance flux underestimates over a grassland; Agric. For. Meteorol. 103 279-300.

Wang K and Dickinson R 2012 A review of global terrestrial evapotranspiration: Observation, modeling, climatology, and climatic variability; Rev. Geophys. 50 RG2005.

Wang K, Dickinson R, Wild M and Liang S 2010 Evidence for decadal variation in global terrestrial evapotranspiration between 1982 and 2002: 1. Model development; J. Geophys. Res. 115 D20112.

Wang Y, Zhou G and Wang Y 2008 Environmental effects on net ecosystem $\mathrm{CO}_{2}$ exchange at half-hour and month scales over Stipa krylovii steppe in northern China; Agric. For. Meteorol. 148 714-722.

Wu S, Yang Q and Zheng D 2003 Delineation of ecogeographic regional system of China; J. Geogr. Sci. 13 309-315.

Xia J, Liang S, Chen J, Yuan W and Liu S et al. 2014 Satellite-based analysis of evapotranspiration and water balance in the grassland ecosystems of Dryland East Asia; PLoS One 9 e97295.

Xiao J, Zhuang Q, Liang E, McGuire A and Moody A et al. 2009 Twentieth century droughts and their impacts on terrestrial carbon cycling in China; Earth Interact. 13 $1-31$.

Yang F, White M, Michaelis A, Ichii K and Hashimoto $\mathrm{H}$ et al. 2006 Prediction of continental-scale evapotranspiration by combining MODIS and AmeriFlux data through support vector machine; IEEE Trans. Geosci. Rem. Sens. $443452-3461$.

Yang F and Zhou G 2011 Characteristics and modeling of evapotranspiration over a temperate desert steppe in Inner Mongolia, China; J. Hydrol. 396 139-147.

Yang C, Yan Z and Shao Y 2012a Probabilistic precipitation forecasting based on ensemble output using generalized additive models and Bayesian model averaging; Acta Meteorol. Sin. 26 1-12.

Yang Y, Xu J, Hong Y and Lv G 2012b The dynamic of vegetation coverage and its response to climate factors in Inner Mongolia, China; Stoch. Environ. Res. Risk A. 26 357-373.

Yao Y, Liang S, Qin Q and Wang K 2010 Monitoring drought over the conterminous United States using MODIS and NCEP Reanalysis-2 data; J. Appl. Meteorol. Clim. 49 1665-1680.

Yao Y, Liang S, Cheng J, Lin Y and Jia K et al. 2014 Impacts of deforestation and climate variability on terrestrial evapotranspiration in subarctic China; Forests 52542 2560.

Yao Y, Liang S, Cheng J, Liu S and Fisher J et al. 2013 MODIS-driven estimation of terrestrial latent heat flux in China based on a modified Priestley-Taylor algorithm; Agric. For. Meteorol. 171-172 187-202 
Yao Y, Zhang Y, Zhao S, Li X and Jia K 2015a Evaluation of three satellite-based latent heat flux algorithms over forest ecosystems using eddy covariance data; Environ. Monit. Assess. 187382.

Yao Y, Liang S, Li X, Chen J and Wang $\mathrm{K}$ et al. 2015b A satellite-based hybrid algorithm to determine the Priestley-Taylor parameter for global terrestrial latent heat flux estimation across multiple biomes; Rem. Sens. Environ. 165 216-233.

Yao Y, Liang S, Li X, Liu S and Chen J et al. 2016 Assessment and simulation of global terrestrial latent heat flux by synthesis of CMIP5 climate models and surface eddy covariance observations; Agric. For. Meteorol. 223 151-167.

Zeng J, Zhang Q and Wang S 2011 Regional differences in the characteristics of clear-sky land surface processes in distinct climatic zones over northern China; Chin. J. Atmos. Sci. 35 483-494 (in Chinese).

Corresponding editor: SURESH BABU
Zhang Q, Xu C, Zhang Z, Chen Y and Liu C 2009 Spatial and temporal variability of precipitation over China, 1951-2005; Theor. Appl. Climatol. 95 53-68.

Zhang K, Kimball J, Mu Q, Jones A and Goetz S et al. 2009 Satellite based analysis of northern ET trends and associated changes in the regional water balance from 1983 to 2005; J. Hydrol. 379 92-110.

Zhang Y, Yao Y, Lin Y and Xiang L 2016 Satellite characterization of terrestrial drought over Xinjiang Uygur Autonomous Region of China over past three decades; Environ. Earth Sci. 75451.

Zhao M and Running S 2010 Drought-induced reduction in global terrestrial net primary production from 2000 through 2009; Science 329 940-943.

Zhao M, Running S and Nemani R 2006 Sensitivity of Moderate Resolution Imaging Spectroradiometer (MODIS) terrestrial primary production to the accuracy of meteorological reanalysis; J. Geophys. Res. 111 G01002. 